\title{
Error Analysis on The Use of Inflectional Morpheme in Student's Writing of Bali State Polytechnic
}

\author{
Ni Made Pramestia Dewi ${ }^{1}$, I Made Madia ${ }^{2}$, Ni Ketut Widhiarcani Matradewi ${ }^{3}$ \\ Tyaprames01@gmail.com \\ Universitas Udayana, Denpasar 80114, Indonesia
}

\begin{abstract}
This study is generally at identifying the errors in the use of inflectional morpheme that was committed by the students and the factors causes of those inflectional morpheme errors. Specifically, the aims of this study focused on identifying the dominant type of errors on the use of inflectional morpheme in students' writing and investigating the possible factors that were caused the errors. The data of this study were obtained and analyzed based on descriptive qualitative research by asking the students to make an essay for an hour. The use of the documentation method used to collect the data as the result of students' writing. The data of this study was qualitatively analyzed based on the surface strategy taxonomy theory proposed by Dulay et al (1982): the addition error, omission error, misformation, and misordering. In addition, other theories about the factors that were caused errors for the interlingual and intralingual proposed by Richard and Schmidt (2002) The analysis of this study was presented in formal and informal methods. Each problem in this study was descriptively presented for an easier understanding. The finding revealed that the students tended to commit omission errors and addition errors in the use of inflectional morpheme. Furthermore, it was found that these inflectional morpheme errors were caused by the intralingual factors. Moreover, based on the type of intralingual factor, the students were found to commit the errors caused by overgeneralization and ignorance of rules restrictions.
\end{abstract}

Key Words: Error Analysis, Inflectional, Students' Writing

\section{Introduction}

Writing skill becomes very important for students besides the other skills because the success of the language learning process depends on the greater part of their ability to write. According to Heaton (1989:138), the writing skill is complex and among the four skills (reading, listening, speaking, and writing), writing can be classified as the most difficult one. Sometimes, it is also difficult to teach the skill since it requires mastering not only grammatical and rhetorical devices such as the control of content, format, sentence structure, vocabulary, punctuation spelling, and so on but also the conceptual and judgment elements.

Belkhir \& Benyelles (2017) state that many EFL (English as a Foreign Language) learners encounter writing difficulties and the major one is linked to English grammar. Based on those statements, it can be concluded that writing is one of the most difficult skills to be mastered in learning the target language. The learners often make mistakes and even errors in learning English, especially when they try to make sentences in writing. The language error cannot be self-corrected until further relevant input is provided and converted into intake by the learner implicitly or explicitly. In other words, the error requires further relevant input to take place before it can be self-corrected. Meanwhile, the mistake can be only corrected by the students 
themselves if the deviance is pointed out to them (James, 2013). The error occurs when the learners do not really know and understand the grammatical rules of the second language that they have learned and grammatical rules can be influenced by the first language which has a different word form from the second language.

The differences are in the terms of grammar, morphology, or equivalence of meaning in both languages. In addition, the learners' errors which can be analyzed, classified and observed to discover something of the system operating within the learner, leading to a surge of study of learners' error is called error analysis (EA). The analysis is needed as a tool to determine how the language learned, by which the learners learned the rules of the target language, and also the profit that can be taken by teachers on the results of the error analysis itself.

One of the most famous methods to analyze the students' errors is called Surface Strategy Taxonomy. It is concerned with how errors come on a surface structure; necessary items learners may omit or add unnecessary ones; they may misform items or misorder them. In other words, Surface Strategy Taxonomy consists of errors in the form of omission, addition, misinformation, and misordering. The types of errors according to this method will be used to classify the errors found in the students' writing.

The rules of English morphological inflection are sometimes easy enough for the students to understand. But some students still make errors because they do not pay attention to it and they do their tasks carelessly. Based on the observations that have been done at the Bali State Polytechnic, it was found that many students still make some errors in writing English essay. One of the examples is they did not add -s for plural inflection. In addition, there are some grammatical rules that are difficult to be understood by the students and they are still confused when they learn about them. For example, they are confused about identifying the use of third person singular inflection. When should they use -s/-es and when they should not. From those explanations, it can be inferred that many students have problems when they learn English morphological inflection. Based on that reason, this study was conducted in order to analyze the students' errors especially in using inflectional morpheme by finding out the types of each inflectional morpheme error and the causes of inflectional morpheme errors made by the students in writing.

\section{Theoretical Framework}

\subsection{Writing}

Writing plays a very important role in language learning. It takes a long time to master this skill since the learners need to do a lot of practice to develop this skill. Patel and Jain (2008: 125) state that writing is a kind of linguistic behavior; a picture is not. It presents the sounds of language through visual symbols. Writing also refers to language skill that involves language production. Therefore, it is known as one of the productive skills. While reading and listening are receptive skills, both writing and speaking are productive skills. Writing is like a tool that produces something such as an article, essay, diary, etc. Brown (2004: 218) says that writing is the main convention for reinforcing grammatical and for recording speech and lexical features of the language.

According to Graham and Perin (2007: 9), writing is a skill that draws on the use of strategies such as planning, evaluating, and revising the text to accomplish a variety of goals such as, writing a report or expressing an opinion with the support of evidence and writing is a means of extending and deepening student's knowledge, it acts as a tool for learning the subject matter. Pilar and Lach (2011:43) also add learning to write for the process approach involves going through the stages of the composing process: planning and outlining the writing, generating idea, writing several drafts, re-reading the text, revising, restructuring, editing, and being able to call on any of these cognitive sub-processes whenever they are 
acquired. In other words, writing is a complex process that converts words into written form. The writer should arrange his/her idea into words, clauses, phrases, and sentences in order that his writing can be read and the content can be understood.

\subsection{Morphological Inflection}

Morphology is both the oldest and the youngest sub-disciplines of grammar (Haspelmath, 2010: 01). It becomes the oldest because as everyone knows, the first linguists were primarily morphologists. On the other hand, the terms phonology (for sound structure) and syntax (for sentence structure) had existed for centuries when the term morphology was introduced. Thus, in this sense morphology is a young discipline. While Lehmann (in Srijono, 2001:49) defines morphology as the study of morphemes, their variation, and their combination in words. A morpheme can be defined as the smallest unit of words that has meaning or serves a grammatical function in a language. Some morphemes are able to stand on their own as words, while other morphemes are only allowed to combine themselves with some other morphemes but they cannot stand by themselves as independent words. Those morphemes that are allowed to stand on their own in sentences as words are called free morphemes. On the other side, the morphemes that should combine themselves with other morphemes are called bound morphemes.

Bound morphemes have two categories. They are derivational morphemes and inflectional morphemes. Derivational morphemes are used to make new words in the language and are often used to make words of a different grammatical category from the root. Whereas inflectional morphemes are not used to produce new words in the English language, but rather to indicate aspects of the grammatical function of a word. Inflectional morphemes are used to show if a word is plural or singular, if it is a past tense or not, etc.

Inflection is the morphological marking of properties on a lexeme resulting in a number of forms for that lexeme, a set of grammatical words (Booij, 2007: 99). In other words, an inflectional morpheme is a morpheme that does not change the words' category and does not create new lexemes, but rather changes the form of lexemes so that they fit into different grammatical contexts or meanings. Grammatical contexts can include information about numbers (singular and plural), a person (first, second, third), tenses (past and present), etc.

\subsection{Error Analysis}

Error Analysis (EA) deals with the learners' performances in terms of the cognitive process they make use of in recognizing or coding the input they receive from the target language. Therefore, the main focus of EA is on the evidence that learners' errors provide an understanding of the underlying process of second language acquisition (Erdogan, 2005). From that statement, Error Analysis (EA) shows that the learner errors were not only from the native language but also from their reflection in some learning strategies. Richards \& Schmidt (2002) also argue that Error Analysis (EA) is a technique for identifying, classifying, and interpreting the unacceptable forms of a language systematically. It occurs in the production data of someone's learning either a second or a foreign language. Error analysis has a big role in teaching a foreign language it is using by the teacher to discover the error made by the students during the learning process.

Moreover, Ellis (1997) discussed that there are stages in doing the error analysis. They are identifying the error, describing the error, and explaining the error. Those points will be explained briefly in the definition below: 
a. Identification of errors.

The first step in analyzing the error is to identify them. To identify the error, the researcher has to take note of the sentences that contain the error and mark them as the error words or phrases. In the identification stage, the researcher needs the correct comparison due to ease the process of analyzing.

b. Description of errors.

The second step in analyzing the error is describing the error. All of the errors that have been identified should be described by using two ways. The first one is classifying the errors based on grammatical categories, for example: identifying errors related to inflectional morphemes. The second way is describing errors based on the surface structure taxonomy, such as omission, addition, misinformation, and misordering.

c. Explanation of errors.

The final step in analyzing the error is explaining each type of error based on the classification. After identifying and describing the error, the researcher should make some explanations based on the classification of error that has been made by students. The explanation can be made in the form of a brief description.

Many linguists who learned about error analysis have a standard which is often called taxonomy. It is a useful method to classify the types of errors that often occur in the second language learner's speech and writing. In this context, a linguist called Dulay et al (1982) formulated Surface Taxonomy Strategy in terms of classification of error in the sentence. The classification of error can be defined as follows:

\section{A. Omission}

Omission errors are characterized by the absence of an item that must appear in a well-formed utterance. Learners often make an incomplete sentence by omitting any morphemes. For example:

There are ten books on the table

The learner makes errors by omitting " $s$ " in the plural form of a phrase or sentence. The errors can be influenced by their native language rules or another reason. In Indonesian, the sentence above is translated as: There are ten books on the table. It does not ruin the meaning when it is translated into Indonesian because there is no "s" as a sign of plural form in the Indonesian rule of language.

\section{B. Addition}

When the omission describes the absence of something important in sentence structure, the opposite of it is called addition errors. It can be characterized by the presence of an item that must not appear in a well-formed utterance. Learners are not only often omitting some morpheme that should appear in a well-formed utterance, but they are also often adding unnecessary items in their word. In the other words, addition is the presence of items that much not appear in a well-formed utterance. It can happen because they are not careful in writing or the other reason.

\section{Misinformation}

Misinformation errors are characterized by the use of the wrong form of the morpheme or structure. Misinformation usually comes in the form of regularizations, archi-forms, and alternating forms. Learners commonly misinform the sentence because of their habit to form a sentence according to their native language. Sometimes they also use wrong morphemes and also ignore important morphemes which can cause ambiguity.

\section{Misordering}

Misordering errors are characterized by the incorrect placement of a morpheme or group of morphemes in an utterance. Misordering can occur in native and foreign language learning. Learners sometimes ignore the correct structure of each sentence used in the target language.

During the process of learning the target language, errors cannot be avoided by the learners. In another opinion, the target language errors made by learners are important for their understanding of the process of target language acquisition. According to Richards and Schmidt (2002: 205), the major causes of errors in 
learning the target language are classified into two namely interlingual errors and intralingual errors. Both of the categories will be explained as follows:

1. Interlingual errors

Interlingual errors are caused by the interference of the learners' native or background language. It happened because the features of the two languages are different. To identify interlingual errors, the learners translate the phrase or sentence of the target language into the learners' first language to see any similarities.

For examples:

a. Balloon pink (It should be pink balloon)

b. $\quad$ Song new (It should be new song)

Based on the examples above, the learner translates noun phrase of English into noun phrase of Bahasa. In English, it should be modifier before the head. As the opposite, in Bahasa, modifier comes after the head.

2. Intralingual errors

Intralingual errors are those that reflect the learners' competence at a particular stage and illustrate some of the general characteristics of language acquisition. Richards states that there are four causes of intralingual errors. They are overgeneralization, ignorance of rules restriction, incomplete application of rules, and false concept hypothesized. Overgeneralization covers the instance where the learner creates a deviant structure on the basis of his/her experience of other structures in the target language. It is including the creation of the deviant structure in place of two target language structures.

\section{Methods}

This study belongs to qualitative research by using a descriptive qualitative approach that is designed to determine the nature of a situation and obtain the information about the phenomena in a current study objectively. The qualitative research approach is usually associated with the social constructivist paradigm which emphasizes the socially constructed nature of reality. This kind of approach refers to recording, analyzing, and attempting the data to discover the deeper and significant meaning, based on the real situation. The data of this study will be taken from the students' writing on using inflectional morpheme.

The aim of qualitative research is not verification of a predetermined idea, but the discovery that leads to new insights. In other words, qualitative research only focuses on natural settings. In addition, Arikunto (2007: 234) says that descriptive research had no hypothesis, but only described some variables and conditions naturally. Based on the explanation above, it can be concluded that in the current study, this approach aims to describe the errors especially in the use of inflectional morpheme made by the secondsemester students at Bali State Polytechnic in writing. It is used to know the common errors made by students especially in using inflection morpheme in their writing and to discover the source of error.

\section{Result and Discussion}

\subsection{The Errors in the use of Inflectional Morpheme}

The data were classified into four types of errors, such as; addition, omission, misordering, and misformation. Meanwhile, the errors in the use of inflectional morphemes were not found for the types of misformation and misordering in their writing. Specifically, the following table was then presented about students' inflectional errors in numbers. 
Table 4.1 Description Types of Students' Errors in Using Inflectional Morphemes.

\begin{tabular}{|c|c|c|c|c|c|}
\hline \multirow{2}{*}{$\begin{array}{c}\text { Students' } \\
\text { Code }\end{array}$} & \multicolumn{4}{|c|}{ Types of Inflectional Errors } & \multirow{2}{*}{ Total } \\
\hline & Addition & Omission & Misordering & Misformation & \\
\hline $1.2 \mathrm{~A}$ & 1 & 3 & - & - & 4 \\
\hline $2.2 \mathrm{~A}$ & - & 5 & - & - & 5 \\
\hline $3.2 \mathrm{~A}$ & 2 & 3 & - & - & 5 \\
\hline $4.2 \mathrm{~A}$ & 1 & 2 & - & - & 3 \\
\hline $5.2 \mathrm{~A}$ & 2 & 3 & - & - & 5 \\
\hline $6.2 \mathrm{~A}$ & 2 & 1 & - & - & 3 \\
\hline $7.2 \mathrm{~A}$ & 2 & 1 & - & - & 3 \\
\hline $8.2 \mathrm{~A}$ & 2 & - & - & - & 2 \\
\hline $9.2 \mathrm{~A}$ & 2 & - & - & - & 2 \\
\hline $10.2 \mathrm{~A}$ & - & 2 & - & - & 2 \\
\hline $1.2 \mathrm{~B}$ & 1 & 4 & - & - & 5 \\
\hline $2.2 \mathrm{~B}$ & 1 & 3 & - & - & 4 \\
\hline $3.2 \mathrm{~B}$ & 2 & 2 & - & - & 4 \\
\hline $4.2 \mathrm{~B}$ & 1 & 4 & - & - & 5 \\
\hline $5.2 \mathrm{~B}$ & 4 & - & - & - & 4 \\
\hline $6.2 \mathrm{~B}$ & 2 & 6 & - & - & 8 \\
\hline $7.2 \mathrm{~B}$ & 1 & 1 & - & - & 2 \\
\hline $8.2 \mathrm{~B}$ & 2 & 2 & - & - & 4 \\
\hline $9.2 \mathrm{~B}$ & 1 & 8 & - & - & 9 \\
\hline $10.2 \mathrm{~B}$ & - & 2 & - & - & 2 \\
\hline 20 & 29 & 52 & & & 81 \\
\hline
\end{tabular}

Table 4.1 above was presented about the total number of students' errors in the use of inflectional morphemes. Moreover, the most inflectional errors for both addition and omission were made by one student with the code 9.2B. In addition, there were also five students who made fewer errors with the codes were 8.2A, 9.2A, 10.2A, 7.2B, and 10.2B. Based on the data above, it can be seen that there were only two out of four types of inflectional errors made by students. Those types were the addition and the omission. Hence, the clear description of the students' total numbers of errors was then represented in the following table.

Table 4.2 The Number of Students who Made Errors in Percentage

\begin{tabular}{cccc}
\hline Number of Errors & Total students & $\%$ & Cumulative \\
\hline 2 errors & 5 students & $25 \%$ & $25 \%$ \\
\hline 3 errors & 3 students & $15 \%$ & $40 \%$ \\
\hline 4 errors & 5 students & $25 \%$ & $65 \%$ \\
\hline 5 errors & 5 students & $25 \%$ & $90 \%$ \\
\hline 8 errors & 1 student & $5 \%$ & $95 \%$ \\
\hline 9 errors & 1 student & $5 \%$ & $100 \%$ \\
\hline
\end{tabular}

The classification data based on the percentage above was revealed that there were 9 inflectional errors were made by $1(5 \%)$ out of 20 students. In the same vein, there was also another $1(5 \%)$ out of 20 students who made 8 inflectional errors for both addition and omission. Moreover, there were 5 inflectional errors made by $5(25 \%)$ out of 20 students. The next was 4 errors made by 5 (25\%) out of 20 students and 3 errors were made by $3(15 \%)$ out of 20 students. Finally, there were $5(25 \%)$ out of 20 students who made 2 errors in the use of inflectional morpheme in their English writing. 
After presenting the number of students who made the errors based on the description above, the following table was presented in order to describe the errors in percentage based on their type.

Table 4.3 Total Errors Based on Its Types in Percentage

\begin{tabular}{cccc}
\hline No & Types of Error & Total Occurrences & Percentage \\
\hline 1 & Addition & 29 & $35.8 \%$ \\
\hline 2 & Omission & 52 & $64.2 \%$ \\
\hline 3 & Misordering & - & - \\
\hline 4 & Misformation & - & - \\
\hline & Total Errors & 81 & $100 \%$ \\
\hline
\end{tabular}

The data presented in the table above was revealed that the students tended to make addition and omission errors in the use of inflectional morphemes. In line with that, the tabulation data based on the students' numbers of errors shows that the number of addition errors made by students in their writing was 29 (35.8\%) out of 81 total errors. In addition, there were $52(64.2 \%)$ out of 81 omission errors made by the students in their writing. Therefore, the dominant errors which were committed by students were the omission errors.

\subsection{The Factors Causing the Errors}

The table below presented the intralingual factors causing errors made by the students based on its type.

Table 4.4 The Over Generalization Factors that Caused Errors

\begin{tabular}{|c|c|c|c|}
\hline Over Generalization & Inflectional Errors & $\Sigma$ & $\%$ \\
\hline \multirow{2}{*}{-s/-es } & Simple Future & 7 & 35 \\
\hline & Possessive Form & 8 & 40 \\
\hline \multirow[t]{2}{*}{-d/-ed } & Passive Voice & 5 & 25 \\
\hline & & 20 & 100 \\
\hline
\end{tabular}

Table 4.4 above about the overgeneralization factors that caused errors made by the students had shown that there were 20 errors. In this case, the students tended to over generalize the suffix -s/-es for the simple future and the possessive form aspects. Meanwhile, as presented in the above table that there were $8(40 \%)$ out of 20 errors caused by the over-generalizing the use of the suffix -s/-es to form the simple future tense, and there 7 (35\%) out of 20 errors caused by the factor of overgeneralization.

In addition, there were $5(25 \%)$ out of 20 errors in the use of the suffix -d/-ed to form the passive voice based on the overgeneralization factor that is causing students' errors. Moreover, the following table presented about the ignorance of rules restriction factor as another type of intralingual which caused students' errors in their writing.

Table 4.5 The Ignorance of Rules Restriction Factors that Caused Errors

\begin{tabular}{cccc}
\hline $\begin{array}{c}\text { Ignorance of rules } \\
\text { Restriction }\end{array}$ & Inflectional Errors & $\Sigma$ & $\%$ \\
\hline -ing & Simple Future & 5 & 8.2 \\
\cline { 2 - 4 } & Simple Present & 12 & 20 \\
\hline -s/-es & Simple Present & 7 & 11 \\
\hline
\end{tabular}




\begin{tabular}{|c|c|c|c|}
\hline & Plural Noun & 35 & 57 \\
\hline -d/-ed & Passive Voice & 2 & 3.3 \\
\hline & $\Sigma$ & 61 & 100 \\
\hline
\end{tabular}

As presented in the table above, the errors were also made because of students' failure to observe the grammatical rules of English in writing especially in the use of suffixes -ing, -s/-es, -d/-ed to form the simple future, simple present, plural noun and the passive voice. The dominant errors based on this type was the use of the suffix - s/-es to form the plural noun aspect and there were $35(57 \%)$ out of 61 errors made. The next was the use of suffix -ing that there were $12(20 \%)$ out of 61 errors to form the simple present aspect. The next is that there were $7(11 \%)$ out of 61 errors made by omitting the suffix $-\mathrm{s}$-es to form the simple present tense. Meanwhile, the suffix -ing was also added after the subject informing the simple future which was 5 (8.2\%) out of 61 errors found. The last, there were only 2 (3.3\%) out of 61 errors were found by directly attaching suffix -ed after the subject.

Moreover, the following table has presented the factor which caused the errors made by students.

Table. 4.10 The Number of Factors Caused Errors

\begin{tabular}{|c|c|c|c|c|c|}
\hline & tors & Suffix & Morphological Errors & $\Sigma$ & $\%$ \\
\hline \multirow{8}{*}{ Intralingual } & \multirow{3}{*}{$\begin{array}{c}\text { Over } \\
\text { Generalization }\end{array}$} & \multirow{2}{*}{-s/-es } & Simple Future & 7 & 8.24 \\
\hline & & & Possessive Form & 8 & 9.41 \\
\hline & & -d/-ed & Passive Voice & 5 & 5.88 \\
\hline & \multirow{5}{*}{$\begin{array}{l}\text { Ignorance of rules } \\
\text { Restriction }\end{array}$} & \multirow{2}{*}{-ing } & Simple Future & 5 & 5.88 \\
\hline & & & Simple Present & 12 & 14.1 \\
\hline & & \multirow{2}{*}{-s/-es } & Simple Present & 7 & 8.24 \\
\hline & & & Plural Noun & 35 & 41.2 \\
\hline & & -d/-ed & Passive Voice & 2 & 2.35 \\
\hline \multirow{2}{*}{\multicolumn{2}{|c|}{ Interlingual }} & \multirow{2}{*}{-s/-es } & Plural Noun & 4 & 57.1 \\
\hline & & & Simple Present & 3 & 42.9 \\
\hline & & & & 88 & 100 \\
\hline
\end{tabular}

The data in the table above had presented the number of errors caused by interlingual and intralingual factors. In line with that, based on its factors that the errors were mostly caused by the intralingual factors which were $88(92 \%)$, and there were only $7(8 \%)$. In this case, the interlingual factor found that hat the students omit the suffix $-\mathrm{s}$ to indicate the plural in the form of adverb of time and omit the suffix $-\mathrm{s} /$-es which is supposed to be attached to the verb 1 indicated the simple present tense after the singular noun. Those errors had also categorized as the type of intralingual factors. Therefore, based on the students writing in the use of inflectional morpheme, the errors were caused by the intralingual errors.

\section{Conclusion}

Based on the result and the discussion of the research conducting, it can be drawn some conclusions, they are;

1. The types of students' error in using inflectional morpheme made by second-semester students of Hospitality and Travel Study Program at Bali State Polytechnic in academic year of 2020/2021 based on surface strategy taxonomy were the addition and omission, found in their sentence.

2. The total number of errors committed by students was 81 items. The percentage of the students' errors in using inflectional morpheme-based on surface strategy taxonomy is as follows: the numbers of addition were $29(35.8 \%)$ out of 81 total errors and omission errors were 52 (64.2\%) out of 81 total errors. Based 
on the percentage of student error above, it can be concluded that the dominant type of error in Bali State Polytechnic student's writing was the omission error which had the highest percentage of error.

3. The factors that caused inflectional morpheme errors in students' writing were intralingual and interlingual. Based on the type of intralingual factor, the students were found to commit the errors caused by overgeneralization and ignorance of rules restrictions. In line with that, the errors were mostly caused by the intralingual factors which were $81(92 \%)$, and there were only $7(8 \%)$ errors caused by the interlingual. The interlingual factor found that hat the students omit the suffix $-\mathrm{s}$ to indicate the plural noun and omit the suffix -s/-es which is supposed to be attached to the verb 1 indicated the simple present tense after the singular noun. Those errors had also been categorized as the type of intralingual factors. Therefore, based on the students writing in the use of inflectional morpheme, the errors were caused by the intralingual factor.

\section{References}

Arikunto, S. 2007. Prosedur Penelitian: Suatu Pendekatan Praktik. Jakarta: PT Rineka Cipta.

Belkhir, A., and Benyelles, R. 2017. Identifying EFL Learners Essay Writing Difficulties and Sources : A Move towards Solution The Case of Second Year EFL Learners at Tlemcen. International Journal of Learning, Teaching and Educational Research, 16(6), page. 80-88.

Booij, G. 2007. The Grammar of Words. An Introduction to Morphology. Second Edition. New York: Oxford University Press Inc.

Brown, H. D. 2004. Language Assessment Principles and Classroom Practices. New York: San Francisco State University.

Dulay, H., Mariana, B., and Stephen, K. 1982. Language Two. Oxford: University Press.

Ellis, R. 1997. Second Language Acquisition. Oxford: Oxford University Press.

Erdogan, V. 2005. Contribution of Error Analysis to Foreign Language Teaching'. Mersin University Journal of The Faculty of Education, Vol. 1/2, Pp. 261-270.

Graham, S., and Perin, D. 2007. Writing Next: Effective Strategies to Improve Writing Of Adolescents in Middle and High Schools. New York: Carnegie Corporation's

Haspelmath, M., and Andrea D. 2010. Understanding Morphology 2nd edition. London: Hodder Education.

Heaton, J. B. 1989. Writing English Language Test. New York: Longman Inc.

James, C. 2013. Errors in Language Learning and Use. New York: Routledge Press.

Patel, M. F., and Jain, M. P. 2008. English Language Teaching: Methods, Tools \& Techniques. Jaipur: Sunrise.

Pilar, M. and Lach, A. 2011. Lexical Errors and Accuracy in Foreign Language Writing. Bristol: Multilingual Matter.

Richards, J. C., and Schmidt, R. 2002. Dictionary Of Language Teaching And Applied Linguistics (3rd ed.). London: Longman.

Srijono, D. 2001. An Introductory Course of Linguistics. Surakarta: Muhammadiyah University Press. 